\title{
The Prevailing 0 Serogroups Among the Serologically Differentiated Clinical Proteus Spp. Strains in Poland
}

Dominika Drzewiecka ( $\nabla$ domkam@biol.uni.lodz.pl)

University of Lodz https://orcid.org/0000-0002-2753-7700

Agata Palusiak

University of Lodz

Małgorzata Siwińska

University of Lodz

Agnieszka Zabłotni

University of Lodz

Original Article

Keywords: Proteus mirabilis, dominating 0 serotypes, lipopolysaccharide, serological variety

Posted Date: February 17th, 2021

DOI: https://doi.org/10.21203/rs.3.rs-201085/v1

License: (9) This work is licensed under a Creative Commons Attribution 4.0 International License.

Read Full License 


\section{Abstract}

In the years 2006-2011, 617 Proteus spp. strains isolated mostly from urine and wounds or other clinical sources from infected individuals were collected in Łódź, Poland. P. mirabilis species was dominating (86.9\%), followed by P. genomospecies, P. vulgaris , and P. penneri . Ninety four per cent strains were recognized as $S$ (smooth) forms. P. mirabilis exhibited the most intensive swarming growth. Serological studies (involving ELISA - enzyme-linked immunosorbent assay and Western blotting using native and adsorbed rabbit antisera) enabled classification of $80 \% \mathrm{~S}$ isolates into respective Proteus 0 serogroups among the 83 ones, described so far. The remaining strains seemed to be serologically unique. Detailed serological analysis confirmed that the recently described in Poland 078 serogroup is the most widespread. Also, 14 other serogroups have been found to predominate, being represented by ten or more strains. No unique structural feature of the prevalent $\mathrm{O}$ serotypes has been indicated. The observed big serological variety may suggest a low rate of Proteus spp. strains' transmission between patients or rapid changes in their lipopolysaccharides. However, the prevalence of some 0 serogroups indicates that particular serotypes may be in some ways beneficial to the strains producing these kinds of 0 antigen.

\section{Introduction}

Proteus spp. bacteria are peritrichously flagellated members of Morganellaceae family distinguished from the other representatives of the order Enterobacterales by intensive and spectacular swarming growth on solid media as a result of the multicellular differentiation phenomenon [1, 2]. These bacilli are detected in natural environments (water or soil) and in many species of wild and domestic animals. They have also been found to be a component of natural faecal microflora in a part of human population. On the other hand, Proteus spp. are opportunistic pathogens, which may affect mainly immunocompromised individuals and cause infections of the urinary tract and wounds, bacteraemia, abscesses in many organs or other infections [3]. Among the pathogenic species, $P$. mirabilis is most common followed by less frequently isolated $P$. vulgaris, $P$. penneri, $P$. hauseri, and three genomospecies without names $(P$. genomospecies 4,5 , and 6 ). Lack of biochemical reactions which would reliably distinguish between different $P$. genomospecies resulted in limited knowledge on their characteristics and isolation frequency $[4,5]$, when compared to well-described $P$. mirabilis. Urinary tract infections (UTIs) of $P$. mirabilis aetiology are frequently catheter-associated - CAUTIs, recurrent and dangerous due to the frequent and severe complications like pyelonephritis and urolithiasis [2].

Among numerous virulence factors of Proteus bacteria, the lipopolisaccharide (LPS) should be emphasized as an endotoxin and an important antigen determining the serological specificity of Proteus spp. strains. The LPS core region in the genus Proteus is structurally and serologically diverse, which has led to the formation of the R typing Proteus scheme containing $11 \mathrm{R}$ serotypes [6]. However, mainly the highly immunogenic 0-polysaccharide region determines the serological specificity of LPS S forms, which has become a basis for the classification of Proteus strains into 830 serogroups $[7,8]$. The first 0 type scheme for $P$. mirabilis and $P$. vulgaris strains including 490 serogroups was founded by Kauffmann [9]. Later, Larsson [10] indicated among them 03, 06, 010, 011, 013, O23, 024, 026, 027, 028, O29, and 
030 as the most prevalent serogroups in many countries. The Kauffmann's scheme was further extended with other $\mathrm{O}$ serogroups containing all Proteus species [7] but only a few $P$. penneri and $P$. mirabilis strains come from Poland [11, 12]. Gathering a new wide collection of more than 600 Proteus spp. clinical isolates from the Łódź region (central Poland) enabled us to study their serological differentiation. Up to date, serologically unique strains from the collection have formed six new serogroups 077-082 [13-18] and two new subgroups in 08 and 011 serogroups $[19,20]$. In this work the serological variety of the whole collection of Proteus spp. strains is shown focusing on Proteus 0 serogroups most widespread in central Poland.

\section{Methods}

\section{Bacterial strains, LPSs, physiological tests}

The studied clinical Proteus spp. strains from different sources (Fig. 1) were kindly provided in 2006-2011 by four big medical laboratories in Łódź (Poland): in Barlicki Hospital, in Biegański Hospital, „Synevo”, „Diagnostyka”. Some strains were isolated from faeces of 189 volunteers using McConkey and Nogrady media plates and recognized as forming the urease-positive and lactose-negative colonies, as described [20]. All isolates were identified by the cultivation on the media proposed by Senior [21], modified as described [13], additional tests were applied for the strains recognized as $P$. genomospecies, as described $[4,15]$ (Table 1). The strains were retained in stocks (Luria Broth cultures with $25 \%$ glycerol) at $-80^{\circ} \mathrm{C}$.

S-R tests included both the thermal stability in the boiled broth medium test and the pseudoagglutination test [22]. Additionally, the swarming growth ability on Luria Broth medium with $1.5 \%$ agar was studied, according to Wilkerson and Niederhoffer [23].

Biomasses of the studied strains were obtained by 18-h cultivation on a nutrient broth medium supplemented with $0.2 \%$ glucose, with aeration, at $37^{\circ} \mathrm{C}$. The strains were killed by $1 \%$ phenol, centrifuged, washed with distilled water and stored in $+4^{\circ} \mathrm{C}$ (wet biomass) or lyophilized (dry biomass).

LPSs were extracted from strains' dry biomass using the classic phenol-water method, published by Westphal and Jann [24].

\section{Serological investigation}

We applied ELISA (enzyme-linked immunosorbent assay) and Western-blotting methods using bacterial biomasses and LPS preparations (extracted from selected studied strains or coming from our collection) as a source of $O$ antigens as well as polyclonal rabbit sera specific to all the $O$ serotypes reported in the genus Proteus (from our collection), as described earlier [15, 25]. In ELISA $50 \mathrm{ng}$ of LPSs or $5 \mu \mathrm{gg}$ of the bacterial biomasses per well were applied for coating the F96 Maxisorp Nunc-Immuno plates. 2,2'-Azinobis(3-ethylbenzothiazoline-6-sulfonic acid) diammonium salt (ABTS) was used as a substrate for peroxidase conjugated with the rabbit-IgG specific goat antibodies (Jackson ImmunoResearch). Antibody 
titers were determined by measuring the absorbance $\left(A_{405}\right)$ using Multiskan Go microplate reader (Thermo Scientific). Additionally, we used some antisera adsorbed by wet bacterial masses, according to the method by Drzewiecka et al. [13]. In Western blotting, antigens (bacterial biomass or LPS, 5-8 $\mu \mathrm{g}$ per lane) were separated during sodium dodecyl sulphate polyacrylamide gel electrophoresis (SDS PAGE). Then, the samples were transferred to nitrocellulose (Whatman Schleicher \& Schuel). The sera were diluted 1:500 in dot-blot-10\% skimmed milk buffer. AP Conjugate Substrate Kit (Bio-Rad) was applied as a substrate of alkaline phosphatase conjugated with the rabbit-lgG specific goat antibodies (Jackson ImmunoResearch).

\section{Results}

\section{Physiological features}

Six hundred and seventeen strains were isolated in the Łódź city, central Poland (Fig. 1), in that number 606 ones from infected individuals. Urine isolates and wound isolates (including bacteria from pus, bedsores, fistulas, skin and wound swabs, and abscesses) were dominating. Other frequent sources of isolation were connected with the respiratory tract (bronchoaspirates, sputum, and the pharyngonasal cavity), faeces, and vagina, while strains from other sources were isolated rarely. Moreover, the bacteria (five $P$. mirabilis strains) were also detected in faecal samples taken from only five out of 181 healthy volunteers $(2.8 \%)$ and in faecal samples from as many as six out of eight infected individuals (four $P$. mirabilis, one $P$. vulgaris, and one $P$. genomospecies $5 / 6$ including four strains reported earlier $[13,14$, 20]). Thus, it was shown that the 11 Proteus spp. strains were inhabiting the intestines of $5.8 \%$ studied volunteers.

The strains species were identified on the basis of the metabolic features of the isolates (Table 1). $P$. mirabilis species was definitely predominant, while the contribution of other detected Proteus species was much lower (Table 1). Totally, 41 isolates (6.6\%) were found to belong to $P$. genomospecies 4 or $5 / 6$, the two last are still impossible to distinguish on the grounds of their metabolic properties [4, 5], while no isolate was classified to $P$. hauseri species. Thus, $P$. genomospecies are isolated from clinical sources with a frequency comparable to that observed for $P$. vulgaris and all the isolates belonging to the so called $P$. vulgaris group together account for $11.7 \%$ of the whole collection, where $P$. genomospecies 4 is the rarest. Contrary to $P$. mirabilis and $P$. penneri (Fig. 1 a,b), among $P$. vulgaris and $P$. genomospecies the isolates from wounds were found to dominate, while the isolates from urine were less common (Fig. 1 $c, d)$. 
Table 1

Biochemical features and frequency of Proteus species occurrence (including the isolates reported earlier [13-20])

\begin{tabular}{|c|c|c|c|c|c|c|}
\hline & \multicolumn{6}{|c|}{ Proteus species } \\
\hline & P. $m$. & P. v. & P.p. & P. $h$. & P. gsp. 4 & P. gsp. 5/6 \\
\hline \multicolumn{7}{|l|}{ Metabolic feature } \\
\hline phenylalanine deaminase & + & + & + & + & + & + \\
\hline mannose fermentation & - & - & - & - & - & - \\
\hline urease production & + & + & + & + & + & + \\
\hline indole production & - & + & - & + & + & + \\
\hline ornithine decarboxylation & + & - & - & - & - & - \\
\hline salicin fermentation & - & + & - & - & - & - \\
\hline esculin hydrolysis & ns & + & ns & - & - & - \\
\hline rhamnose fermentation & ns & ns & ns & - & + & - \\
\hline lipase production & ns & ns & ns & - & + & + \\
\hline DNase production & ns & ns & ns & - & + & + \\
\hline \multicolumn{7}{|l|}{ Frequency } \\
\hline strains no & 536 & 31 & 9 & 0 & 9 & 32 \\
\hline percentage & $86.9 \%$ & $5 \%$ & $1.5 \%$ & $0 \%$ & $1.5 \%$ & $5.2 \%$ \\
\hline \multicolumn{7}{|l|}{ ns, not studied } \\
\hline \multicolumn{7}{|l|}{ P.m., Proteus mirabilis } \\
\hline \multicolumn{7}{|l|}{ P.v., Proteus vulgaris } \\
\hline \multicolumn{7}{|l|}{ P.p., Proteus penneri } \\
\hline \multicolumn{7}{|l|}{ P.h., Proteus hauseri } \\
\hline P.gsp., Proteus genomospe & & & & & & \\
\hline
\end{tabular}

Thirty seven studied strains ( $6 \%$ of the collection) which were totally or partly non-thermal stable and agglutinated in $0.85 \% \mathrm{NaCl}$ were recovered as $\mathrm{R}$ or S/R forms possessing LPS deficient in 0 polysaccharide or LPS with only one O-repeating unit, respectively. R forms constituted only $4.9 \%$ of $P$. mirabilis strains (26 out of all collected P. mirabilis isolates), while in P. vulgaris it was $9.7 \%$ (three out of 
$31 P$. vulgaris isolates), in $P$. genomospecies 4 and $5 / 6-14.6 \%$ (six out of 41 isolates), and in $P$. penneri$22.2 \%$ (two out of nine isolates). As expected, the majority of $\mathrm{R}$ strains were not able to swarm on the surface of solid Luria Broth medium. However, among the smooth strains, the non-swarming ones were also detected. Most of $P$. mirabilis isolates (more than $90 \%$ ) were found to be able to swarm and $70 \%$ exhibited intensive swarming growth (on the distance $>30 \mathrm{~mm}$ within $24 \mathrm{~h}$ ). In the case of $P$. penneri, nonswarming strains constituted $22 \%$ ( $R$ forms only) while the other isolates were able to swarm effectively. The weakest swarming growth ability was observed among $P$. vulgaris and $P$. genomospecies isolates as $50 \%$ of strains have not showed this ability or could swarm very weakly $(<10 \mathrm{~mm}$ within $24 \mathrm{~h})$.

\section{Serological features}

A total of the $580 \mathrm{~S}$ strains (possessing an 0 antigen in the LPS molecules) were serologically investigated to classify them into proper 0 serogroups in the genus Proteus. The results for 24 of these strains classified to $02,08,011,077-082$ serogroups, respectively, had been reported previously [13-20]

Biomasses of the $S$ strains were studied in ELISA with rabbit polyclonal antisera specific to all the Proteus 0 serogroups described so far. Strong cross reactions comparable to the ones in the homologous systems (mostly to the titre 1:128000 or more) were the first indication on the serological type of the studied strains. But the obtained results were not always so clear.

Several biomasses were not recognized by any antisera (the 0 antigens present on the cells were possible to be masked by other cell wall components) and some cross reacted with more than one antiserum achieving various titres (other surface antigens may have also been recognized by the antibodies present in the used rabbit antisera). In these cases, LPS preparations were extracted from the biomasses by the phenol-water procedure [24]. Purified LPS antigens coated on the ELISA plates might be better exposed and better accessible to specific antibodies. Indeed, in consequence the 0 serotype of several such strains was identified.

These results allowed to recognize the similarity of most of the isolates (447/556 S forms studied in this work) to particular $\mathrm{O}$ serotypes among 83 Proteus $\mathrm{O}$ serogroups recognized so far, while the remaining strains seemed to be serologically unique and were considered to represent new 0 serogroups in the genus Proteus. One hundred and fifty six isolates have been preliminarily classified into 470 serogroups (datat not shown) formed by fewer than 10 studied strains. More than a half (291) of the studied here $556 \mathrm{~S}$ Proteus spp. clinical strains were initially considered as belonging to 14 predominating 0 serogroups consisting of 10 or more strains: $03,06,010,011,016,018,020,027,028,030,050,060$, 077, and 078.

To confirm that consideration, the sera specific to the 14 most prevalent 0 serotypes were adsorbed by the cross-reacting biomasses and their reactions with the homologous LPSs were analyzed in ELISA. In most cases, the reactions of the antisera in the homologous systems were totally abolished due to the 
removal of all LPS-specific antibodies by the cross-reacting biomasses, indicating their antigenic identity and confirming the initial serological classification (Table 2). However, in some cases the adsorption was not complete and some remaining fractions of antibodies still reacted with homologous LPSs, although the reactions were obviously weaker than the ones of the native antisera (Table 2). In these 34 cases, some differences in the strains serospecificity were responsible for not full adsorption of the antisera.

Table 2

Cross reactions of studied strains with the respective 0 antisera (native and adsorbed by the studied strains' biomass) in ELISA.

\begin{tabular}{|c|c|c|c|}
\hline \multirow{2}{*}{$\begin{array}{l}\mathrm{O} \\
\text { antiserum }\end{array}$} & \multicolumn{3}{|c|}{ Reciprocal titre of antiserum reacting with } \\
\hline & $\begin{array}{l}\text { homologous } \\
\text { LPS }\end{array}$ & $\begin{array}{l}\text { studied strains } \\
\text { biomass }\end{array}$ & $\begin{array}{l}\text { homologous LPS after adsorption (number of } \\
\text { adsorbing strains) }\end{array}$ \\
\hline 03 & 256,000 & $32,000-512,000$ & $<1,000(17)$ \\
\hline 06 & $64 / 128,000$ & $32,000-128,000$ & $2,000-0, \cup 00(4)$ \\
\hline 010 & 512,000 & $64,000-512,000$ & $<, 000(19)$ \\
\hline 011 & 256,000 & $64,000-512,000$ & $4,000-32,000(12)$ \\
\hline 016 & 256,000 & $32,000-512,000$ & $\begin{array}{l}<1,000(31) \\
2,000-4,000(2)\end{array}$ \\
\hline 018 & 128,000 & $64,000-512,000$ & $<1000$ (22) \\
\hline 020 & 512,000 & $\begin{array}{l}256,000- \\
2,048,000\end{array}$ & $16,000-64,000(3)$ \\
\hline 027 & $1,024,000$ & $64000-2048000$ & $<1,000(11)$ \\
\hline 028 & $64 / 128,000$ & $32,000-512.000$ & $<1,000(24)$ \\
\hline 030 & 512,000 & 128,000- & $<1,000(18)$ \\
\hline 050 & $64 / 128,000$ & $1,024,000$ & $\begin{array}{l}<1,000(13) \\
4,000(2)\end{array}$ \\
\hline 060 & 512,000 & $32,000-5 \mid 2,000$ & $<1,000(12)$ \\
\hline 077 & 256,000 & $64,000-512,000$ & \\
\hline 078 & $512 / 1,024,000$ & $64,000-512,000$ & $4,000(1)$ \\
\hline & & $32,000-512,000$ & $<1,000-1,000(10)$ \\
\hline & & & $<1,000(16)$ \\
\hline & & & $\begin{array}{l}<1,000(44) \\
2,000-32,000(10)\end{array}$ \\
\hline
\end{tabular}

The nature of the cross reactions, observed in ELISA, was visualized in the Western-blotting method using LPS preparations obtained by proteinase-K treated biomasses as antigens (Fig. 2-4). The reactions are similar and comparable to the ones observed for the LPS preparations obtained using phenol-water 
extraction, which is demonstrated on the example of strains classified to 077 serogroup (Fig. 2a,b). By the degradation of proteins, we could remove possible non-specific cross reactions caused by protein antigens rather than by 0 antigens [26]. Indeed, the initially observed in ELISA reactions of several biomasses not fully adsorbing the respective antisera, could have been caused by protein antigens, as they were not confirmed in Western blots. That was the case of four strains (Fig. 3b, paths 2-5) preliminarily classified into 010 serogroup, two strains (Fig. 3c, paths 8, 9) classified into 028 serogroup, and one strain (Fig. 3d, path 8) classified into 050 serogroup, which displayed completely no reaction after proteinase-K treatment in Western blots.

The Western-blotting technique also allowed localizing LPS epitopes responsible for the strong cross reactions initially observed in ELISA. The epitopes may have been present in the 0-specific part and/or in the core region of the LPSs exposed on the biomasses of the studied strains. Indeed, among the strains preliminarily classified into 010 serogroup on the basis of strong reactions of their biomasses in ELISA, one isolate showed in Western blot reactions only in the fast-migrating fractions corresponding to the lipid A-core region, while there were no reactions observed for the slowly migrating LPS bands additionally possessing 0-polysaccharide chains (Fig. 3b, path 8). Similar results were obtained in the case of as many as four strains (Fig. 3a, paths $2,6,7$, and 9) initially classified into 03 serogroup. The 03 and 010 antisera are visibly rich in antibodies recognizing core-localized common epitopes and responsible for strong cross reactions observed both in ELISA and in Western-blots. Obviously, these five strains cannot be included in 03 or 010 serogroups, although they may form $\mathrm{R}$ serogroups.

Noteworthy, the 15 strains initially classified into the most numerous 078,016 , and 011 serogroups but not fully adsorbing the respective 078,016 , or 011 antisera (Table 2) displayed in Western blots visible strong reactions of the slowly-migrating LPS molecules possessing 0 polysaccharides (O-PS), which is showed on the example of the strains (2-7) classified to 078 serogroup (Fig. 4a, paths 2-7). The use of the 078,016 , or 011 antisera adsorbed by the respective biomasses in the Western-blotting technique proved that the observed serological differences refer mainly to the 0-specific parts of these strains' LPS. As the antisera contain small amounts of anti-core antibodies, the possible differences in core antigens were hard to be detected. The adsorbed 078, 016, and 011 antisera did not react with the respective adsorbing biomasses, which confirmed the properly conducted adsorption processes (control), but still in these three antisera there were remaining some fractions of antibodies recognizing the epitopes located in the homologous 0 antigens (slowly-migrating LPS bands) but absent in the studied strains. The Western-blotting results for these 15 strains were similar and they are shown on the example of 078 antiserum adsorbed with strain 2 (Fig. 4b). Thus, the 15 strains were recognized as representing different subgroups within 078,016 , or 011 serogroups, respectively.

\section{Discussion}

In the years 2006-2011 a total of 617 Proteus spp. strains were collected in Łódź, Poland (Fig. 1) including the 24 clinical strains reported earlier [13-20]. What is worth noticing, no strains were collected from blood, although Proteus spp. bacteria may also cause severe bacteremia and sepsis [2, 27]. Urine 
and wound isolates were prevailing especially among the ubiquitous $P$. mirabilis. Frequent isolation of $P$. mirabilis (Table 1) is not surprising, as the species is regarded as the most virulent and widespread species in the genus Proteus, especially in patients suffering from nosocomial urinary tract and wound infections and it is still the most frequently isolated species among Proteus spp. [2]. P. genomospecies 4, 5,6 , or $P$. hauseri are not usually distinguished from $P$. vulgaris in the routine laboratory work and so there are very few reports available on their occurrence in patients. In comparison, O'Hara et al. [4] and Janda et al. [5] studying several $P$. hauseri, $P$. genomospecies 4,5 , and 6 strains, mostly from human sources, found $P$. genomospecies 5 and 6 to be the most numerous. Our result confirm the low frequency of $P$. penneri isolation from clinical sources $[28,29]$. $\mathrm{R}$ forms which are regarded as less virulent, were found among the isolates belonging to all the identified Proteus species. However, in the most pathogenic $P$. mirabilis species, the smallest number of $\mathrm{R}$ forms was detected and the best swarming ability was noticed. The feature of swarming is considered to be an important virulence factor of $P$. mirabilis bacteria and may be a form of their adaptation to the host environment (especially urinary tract). Moreover, $P$. mirabilis swarming cells facilitate an entry into the urinary tract of other non-motile species, which often leads to following polymicrobial UTIs [30]. P. vulgaris isolates demonstrated weaker swarming growth in comparison to P. penneri strains, similarly to the results achieved by Kwil et al. [30].

Serological studies confirmed that the studied strains possess various core types which is typical in the genus Proteus. Frequently, strains forming a common R serogroup do not belong to a common 0 serogroup and the strains classified into one 0 serogroup may differ in their core-region serospecificity [6, 11]. Thus, the use of antisera which are rich in core-specific antibodies is informative, but in the studies aimed at classifying Proteus spp. strains into proper 0 serogroups may be misleading. [19]. A good solution might be the use in the preliminary classification studies of the antisera deprived of core-specific antibodies removed by adsorption, which is hard to obtain, or the application of further detailed tests allowing a precise serological classification of strains on the basis of their $\mathrm{O}$ antigens serospecificity, as presented in this work. Among the studied strains, 13 isolates preliminarily classified into the respective predominating $\mathrm{O}$ serogroups were further excluded on the basis of subsequent detailed studies.

Our studies showed a big serological diversity among Proteus spp. strains isolated recently from patients in central Poland. However, half of the isolates (299) including 18 strains reported before [13-15, 19] belong to 15 most numerous 0 serogroups, comprising ten or more studied strains (Fig. 5). 078 serogroup is the biggest one, formed by 61 studied strains ( $10.5 \%$ of 580 collected $S$ strains). This serogroup together with 077 and 079 serogroups were described as new ones not long ago by Drzewiecka et al. $[13,14]$ and Arbatsky et al. [15] and they currently include only the isolates from Poland. 050 serogroup, in turn, was reported in 2003 [32] and has so far been represented by $P$. mirabilis strain TG 332 described earlier as being serologically unique [33]. 060 serogroup was also formed in 2003 [34] for a non-clinical $P$. myxofaciens isolate from a gypsy larva. Lately, the species has been proposed to be excluded from the genus Proteus [35]. However, our results clearly indicate that 060 serotype exists among $P$. mirabilis and $P$. genomospecies clinical strains. The other 10 most prevalent serogroups have been included in the first classic serological scheme proposed for $P$. mirabilis and $P$. vulgaris bacteria [9]. What is interesting, the majority of these predominant serogroups had been previously reported as 
frequently found among hundreds of clinical $P$. mirabilis and $P$. vulgaris isolates from urine, faeces, blood, or unknown sources. Summarizing these data, Larsson [10] indicated 03 serogroup as dominating in all reports and 010, 013, 026, 028, and 030 serogroups as the most prevalent ones. 06, 011, 023, 024, 027, and 029 serogroups were also widely distributed. Analyzing the serological properties of 99 Swedish and 24 Polish $P$. mirabilis strains from urinary tract infections, Kaca et al. [12] also found 010 and 030 to be the most numerous serogroups. However, the authors applied only 20 Proteus 0 -specific sera in their studies so the attachment of the strains to the other prevalent serogroups (e.g. 06, 026, 028, or 029) was not analysed. Research on $P$. penneri strains revealed that clinical strains and isolates from faeces of healthy people in the USA, Great Britain, Canada, France, Germany, and single strains from other countries belonged mostly to $017,061,064$, and 065 serogroups $[11,36]$ including also $P$. mirabilis and/or $P$. vulgaris strains [7]. In the presented studies three $P$. penneri isolates were classified into 010 serogroup. Several $P$. genomospecies strains were classified into $011,060,078$, and 079 serogroups and two $P$. vulgaris isolates into 027 and 078 serogroups. Thus, some of the prevalent serogroups turned out to be multi-species (Table 3), including not only the ubiquitous $P$. mirabilis but also the other species.

078,016 , and 011 serogroups seem to be heterogenous. Further chemical analysis may show the differences in the structures of $\mathrm{O}$ antigens, responsible for their slight serological variety observed within these serogroups and will allow the formation of new subserogroups or new cross-reacting 0 serogroups.

It can be seen that for many years, Proteus spp. strains belonging to $03,06,010,011,027,028$, and 030 serogroups have been most frequently isolated in many different countries. What is worth noticing, the Proteus 060 antigen structure resembles that of the Proteus 030 antigen [7] so before the 060 serogroup was created in 2003 [34], 060 isolates could be classified to 030 serogroup due to their mutual similarity and strong cross reactivity revealed in our work (data not shown). It should be noted that at present, 078 serogroup obviously seems to be the most prevalent among Polish patients from the Łódź region accounting for $10.5 \%$ of all $\mathrm{S}$ isolates, although its predominance is not big. The prevalence of the serotypes dominating over others may be connected with some features of their $\mathrm{O}$ antigens. However, it is difficult to indicate common structural O-PS features (Table 3) distinguishing the biggest serogroups from the smaller ones, e.g. the compounds present exclusively in the frequent $\mathrm{O}$ antigens and, simultaneously, absent in the rarely found 0 serotypes [7]. Among the 15 most numerous serotypes, both branched and linear O-PS repeating units can be found, which are built of three-to-five sugars, including glucose, galactose, and their derivatives frequently occurring in Proteus 0-PSs. The rest of 2-amino-2deoxy-D-glucose ( $\mathrm{D}-\mathrm{GlcN}$ ) is the most frequent constituent building all the dominating serotypes except 03, however, it is also the most widely distributed component of Proteus 0 serotypes [7]. Some of these frequent $\mathrm{O}$ antigens contain also rare sugars like altruronic acid or deoxytalose and other compounds like amino acids or ribitol phosphate and all of them are acetylated. None of these features is exceptional or atypical for Proteus 0 antigens. For example, the repeating unit of the most ubiquitous 078 antigen is composed of five different sugars and sugar derivatives. Three of them constitute the main chain and two form side branches. This antigen is not characterized by any unusual or unique structural feature. It shares disaccharide fragments with several Proteus 0 antigens, but no cross reactions have been noticed [14].

Page 10/19 


\section{Conclusion}

In general, clinical Proteus spp. isolates from central Poland are characterized by high serological diversity and include the representatives of almost all described $O$ serogroups. These results may suggest that either Proteus spp. strains do not intensively transmit from one patient to another or they are able to rapidly change their antigenic specificity by avoiding the immune response from host organisms, increasing their own virulence and adapting to environmental conditions. Such examples of antigenic variation are known in other Gram-negative genera and may be caused either by mutations in 0 antigen genes or by inter/intra-species lateral transfer of 0 antigen genes by homologous recombination, IS elements, plasmids, or bacteriophages [37].

The genus Proteus is currently divided into 830 serogroups [8] and their number continually grows exceeding numbers of serogroups in many other Gram-negative bacteria like the genera: Shigella or Salmonella (each 460 serogroups), Yersinia ( 350 serogroups), Citrobacter (43 0 serogroups), Pseudomonas ( 300 serogroups), and others, except for Escherichia coli ( 180 0 serogroups) and Vibrio cholerae ( 200 0 serogroups) [37, 38]. Despite the high serological diversity among Proteus bacilli, the results of the presented research confirm the persisting for many years predominance of some serogroups reported earlier [10] and reveal new prevalent 0 serotypes (especially 078). The presence of the representatives of different Proteus species among these serogroups suggests that the bacteria acquire these special $O$ phenotypes as a result of adaptation in convergence processes. Thus, these 0 antigens may be in some ways attractive and beneficial to the expressing bacteria. It will be reasonable to investigate a clonal homology of one-species isolates belonging to the respective predominating 0 serogroups. Their diversity would confirm the special role of a particular 0-antigen type in their survival and virulence.

The appointment of the most virulent 0 serotypes among the Proteus spp. bacilli would allow developing methods, which might enable rapid detection and eradication of such strains.

\section{Declarations}

\section{Acknowledgement}

Financially supported by grant no. N N401 020135 from the Ministry of Science and Higher Education (Poland).

\section{Authors contribution:}

Dominika Drzewiecka led the project and acquired the funding. All authors contributed to the study conception and design. Material preparation, data collection and analysis were performed by all authors. The first draft of the manuscript was written by Dominika Drzewiecka and all authors commented on previous versions of the manuscript, read and approved the final manuscript. 


\section{Data availability statement:}

The data and materials are available from the corresponding author on reasonable request.

\section{Compliance with Ethical Standards}

\section{Ethical approval:}

No approval of research ethics committees was required.

\section{Conflict of interest:}

The authors declare no conflict of interest.

\section{Statement of Informed Consent:}

All authors approve the final draft of the publication and consent to submission.

\section{References}

1. Adeolu M, Alnajar S, Naushad S, Gupta RS (2016) Genome-based phylogeny and taxonomy of the 'Enterobacteriales': proposal for Enterobacterales nov. divided into the families Enterobacteriaceae, Erwiniaceae fam. nov., Pectobacteriaceae fam. nov., Yersiniaceae fam. nov., Hafniaceae fam. nov., Morganellaceae fam. nov., and Budviciaceae fam. nov. Int J Syst Evol Microbiol 66:5575-5599, https://doi.org/10.1099/ijsem.0.001485

2. Armbruster CE, Mobley HLT, Pearson MM (2018) Pathogenesis of Proteus mirabilis EcoSal Plus 8:1123, https://doi.org/10.1128/ecosalplus.ESP-0009-2017

3. Drzewiecka D (2016) Significance and roles of Proteus bacteria in natural environments. Microb Ecol 72:741-758, https://doi.org/1007/s00248-015-0720-6

4. O'Hara CM, Brenner FW, Steigerwalt AG, Hill BC, Holmes B, Grimont PAD, Hawkey PM, Penner JL, Miller JM, Brenner D (2000) Classification of Proteus vulgaris biogroup 3 with recognition of Proteus hauseri nov., nom. rev. and unnamed Proteus genomospecies 4, 5 and 6. Int J Syst Evol Microbiol 50:1869-1875

5. Janda JM, Abbot SL, Khashe S, Probert W (2001) Biochemical identification and characterization of DNA groups within the Proteus vulgaris J Clin Microbio/ 39(4):1231-1234

6. Palusiak A (2016) Classification of Proteus penneri lipopolysaccharides into core region serotypes. Med Microbiol Immunol 205:615-624, https://doi.org/1007/s00430-016-0468-8 
7. Knirel YA, Perepelov AV, Kondakova AN, Senchenkova SN, Sidorczyk Z, Różalski A, Kaca W (2011) Structure and serology of 0-antigens as the basis for classification of Proteus Innate Immun 17:7096, https://doi.org/10.1177/1753425909360668

8. Siwinska M, Zablotni A, Levina EA, Shashkov AS, Ovchinnikova OG, Rozalski A, Knirel YA (2020) The unique structure of bacterial polysaccharides - immunochemical studies on the 0 antigen of Proteus penneri 4034-85 clinical strain classified into a new 083 Proteus Int J Biol Macromol 163:1168-1174, https://doi.org/10.1016/j.ijbiomac.2020.07.012

9. Kauffmann F (1966) Proteus. In: Kauffmann F (ed) The bacteriology of Enterobacteriaceae. Munksgaard, Copenhagen, pp 333-360

10. Larsson P (1984) Serology of Proteus mirabilis and Proteus vulgaris. Methods Microbiol 14:187-214

11. Drzewiecka D, Zych K, Sidorczyk Z (2004) Charaterization and serological classification of a collection of Proteus penneri clinical strains. Arch Immunol Ther Exp 52:121-128

12. Kaca W, Glenska J, Lechowicz L, Grabowski S, Brauner A, Kwinkowski M (2011) Serotyping of Proteus mirabilis clinical strains based on lipopolysaccharide 0 polysaccharide and core oligosaccharide structures. Biochemistry (Moscow) 76(7):851-861, https://doi.org/10.1134/S0006297911070169

13. Drzewiecka D, Arbatsky NP, Shashkov AS, Stączek P, Knirel YA, Sidorczyk Z (2008) Structure and serological properties of the 0 -antigen of two clinical Proteus mirabilis strains classified into a new Proteus 077 serogroup. FEMS Immunol Med Microbiol 54:185-194, https://doi.org/1111/j.1574695X.2008.00462.x

14. Drzewiecka D, Arbatsky NP, Stączek P, Shashkov AS, Knirel YA, Sidorczyk Z (2010) Structural and serological studies of the 0-polysaccharide of strains from a newly created Proteus 078 serogroup prevalent in Polish patients. FEMS Immunol Med Microbiol 58:269-276, https://doi.org/1111/j.1574695X.2009.00632.x

15. Arbatsky NP, Drzewiecka D, Palusiak A, Shashkov AS, Zabłotni A, Siwińska M, Knirel YA (2013) Structure of a Kdo-containing $O$ polysaccharide representing Proteus 079, a newly described serogroup for some clinical Proteus genomospecies isolates from Poland. Carbohydr Res 379:100105, https://doi.org/1016/j.carres.2013.07.001

16. Siwińska M, Levina EA, Ovchinnikova OG, Drzewiecka D, Shashkov AS, Różalski A, Knirel YA (2015) Classification of a Proteus penneri clinical isolate with a unique O-antigen structure to a new Proteus serogroup, 080. Carbohydr Res 407:131-136, https://doi.org/1016/j.carres.2015.02.003

17. Zablotni A,Arbatsky NP, Drzewiecka D, Shashkov AS, Knirel YA (2018) Chemical characterization and serological properties of a unique 0-polysaccharide of the Proteus mirabilis Sm 99 clinical strain - identification of a new, 081, serotype. Int J Biol Macromol 118:1131-1135, https://doi.org/1016/j.ijbiomac.2018.06.174

18. Siwinska M, Levina EA, Shashkov AS, Kalinchuk NA, Drzewiecka D, Knirel YA (2019) Structural and serological characterization of the 082 antigen of a Proteus mirabilis strain isolated from a patient in Poland. Carbohydr Res 486, https://doi.org/1016/j.carres.2019.107831 
19. Drzewiecka D, Arbatsky NP, Kondakova AN, Shashkov AS, Knirel YA (2016) Structures and serospecificity of threonine-containing $O$ polysaccharides of two clinical isolates belonging to the genus Proteus and their classification into 011 subserogroups. J Med Microbiol 65(11):1260-1266, https://doi.org/1099/jmm.0.000360

20. Drzewiecka D, Shashkov AS, Arbatsky NP, Knirel YA (2016) Immunochemical characterization of the $\mathrm{O}$ antigens of two Proteus strains, 08-related antigen of Proteus mirabilis $12 \mathrm{~B}-\mathrm{r}$ and 02-related antigen of Proteus genomospecies 5/6 12 B-k, infecting a hospitalized patient in Poland. Microbiology 162:789-797, https://doi.org/1099/mic.0.000274

21. Senior BW (1997) Media and tests to simplify the recognition and identification of members of the Proteeae. J Med Microbiol 46:39-44

22. Kotełko K, Gromska W, Papierz M, Sidorczyk Z, Krajewska D, Szer K (1977) Core region in Proteus mirabilis J Hyg Epidemiol Microbiol Immunol 21:271-284

23. Wilkerson ML, Niederhoffer EC (1995) Swarming characteristics of Proteus mirabilis under anaerobic and aerobic conditions. Anaerobe 1:345-350

24. Westphal O, Jann K (1965) Bacterial lipopolysaccharides. Extraction with phenol-water and further applications of the procedure. Methods Carbohydr Chem 5:83-89

25. Sidorczyk Z, Zych K, Toukach FV, Arbatsky NP, Zabłotni A, Shashkov AS, Knirel YA (2002) Structure of the O-polysaccharide and classification of Proteus mirabilis G1 in Proteus serogroup 03. Eur J Biochem 269:1406-1412, https://doi.org/1046/j.1432-1033.2002.02782.x

26. Palusiak A (2015) The antigens contributing to the serological cross-reactions of Proteus antisera with Klebsiella Mol Immunol 64:228-234, https://doi.org/10.1016/j.molimm.2014.11.016

27. Kim B-N, Kim NJ, Kim M-N, Kim YS, Woo J-H, Ryu J (2003) Bacteraemia due to tribe Proteeae: a review of 132 cases during a decade (1991-2000). Scand J Infect Dis 35:98-103

28. Drzewiecka D, Sidorczyk Z (2005) Characterization of Proteus penneri species - human opportunistic pathogens. Post Mikrobiol 44:113-126 (in Polish)

29. Palusiak A (2013) Immunochemical properties of Proteus penneri lipopolysaccharides - one of the major Proteus virulence factors. Carbohydr Res 380:16-22, https://doi.org/10.1016/j.carres.2013.06.025

30. Armbruster ChA, Mobley HLT (2012) Merging mythology and morphology: the multifaceted lifestyle of Proteus mirabilis. Nat Rev Microbiol 10:743-754, https://doi.org/1038/nrmicro2890

31. Kwil I, Kaźmierczak D, Różalski A (2013) Swarming growth and resistance of Proteus penneri and Proteus vulgaris strains to normal human serum. Adv Clin Exp Med 22(2):165-175

32. Kołodziejska K, Kondakova AN, Zych K, Senchenkova SN, Shashkov AS, Knirel YA, Sidorczyk Z (2003) Structure of the O-polysaccharide of a serologically separate strain of Proteus mirabilis, TG 332, from a new proposed Proteus serogroup 050. Carbohydr Res 338(20):2105-2109

33. Penner JL, Hennessy JN (1980) Separate O-grouping schemes for serotyping clinical isolates of Proteus mirabilis and Proteus vulgaris. J Clin Microbiol 12:304-309 
34. Sidorczyk Z, Kondakova AN, Zych K, Senchenkova SN, Shashkov AS, Drzewiecka D, Knirel YA (2003) Structure of the 0-polysaccharide from Proteus myxofaciens. Classification of the bacterium into new Proteus 0 serogroup. Eur J Biochem 270:3182-3188

35. Giammanco GM, Grimont PA, Grimont F, Lefevre M, Giammanco G, Pignato S (2011) Phylogenetic analysis of the genera Proteus, Morganella, and Providencia by comparison of rpoB gene sequence of type and clinical strains suggests the reclassification of Proteus myxofaciens in a new genus, Cosenzaea nov., as Cosenzaea myxofaciens comb. nov. Int J Syst Evol Microbiol 61:1638-1644, https://doi.org/10.1099/ijs.0.021964-0

36. Sidorczyk Z, Toukach FV, Zych K, Arbatsky NP, Drzewiecka D, Ziółkowski A, Shashkov AS, Knirel YA (2002) Structural and serological characterization of the lipopolysaccharide from Proteus penneri 20 and classification of the cross-reacting Proteus penneri strains 10, 16, 18, 20, 32 and 45 in Proteus serogroup 017. Arch Immunol Ther Exp 50:345-350

37. Wang L, Wang Q, Reeves PR (2010) The variation of O-antigens in gram-negative bacteria. In: Wang X, Quinn PJ (eds) Endotoxins: structure, function and recognition, Springer, Dordrecht, Heidelberg, London, New York, pp 123-152

38. Knirel YA (2011) Structure of O-antigens. In: Knirel YA, Valvano MA (eds) Bacterial lipopolysaccharides. Structure, chemical synthesis, biogenesis and interaction with host cells, Springer, Wien, New York, pp 41-116

\section{Table}

Due to technical limitations, table 3 is only available as a download in the Supplemental Files section.

\section{Figures}

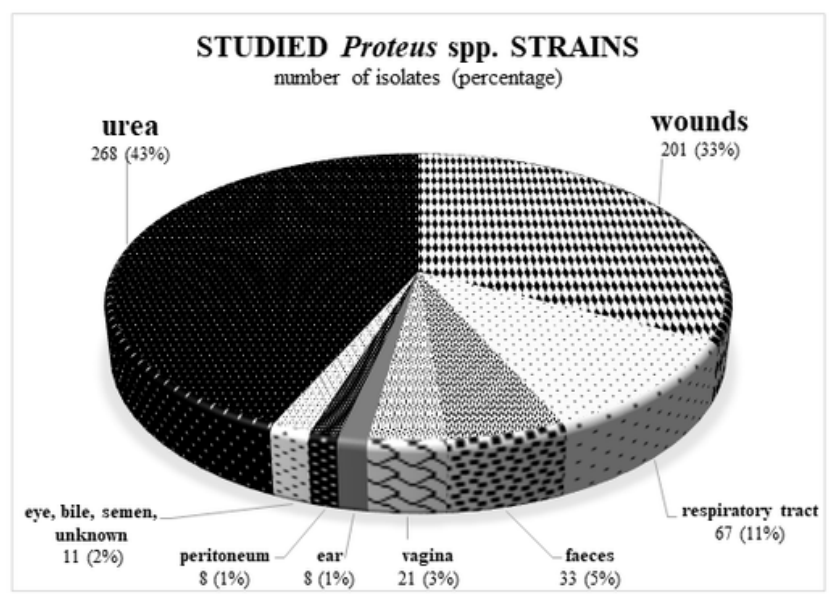

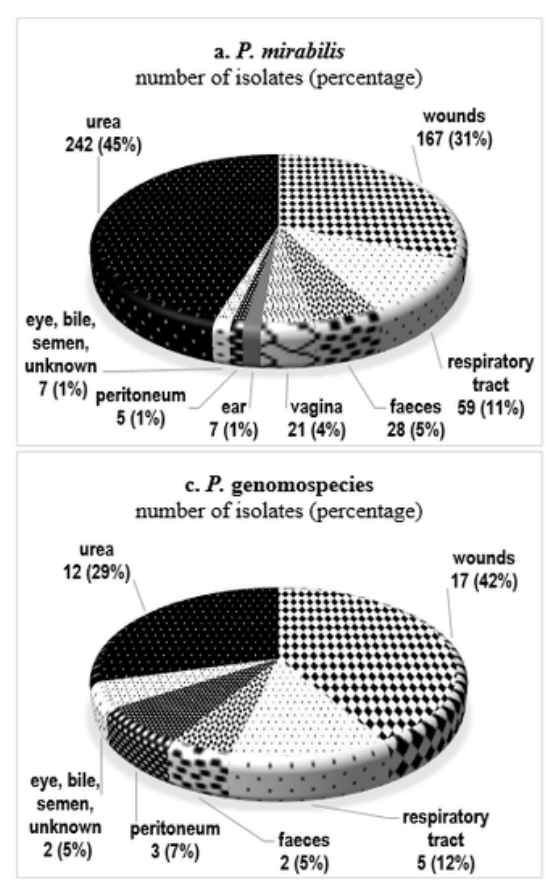

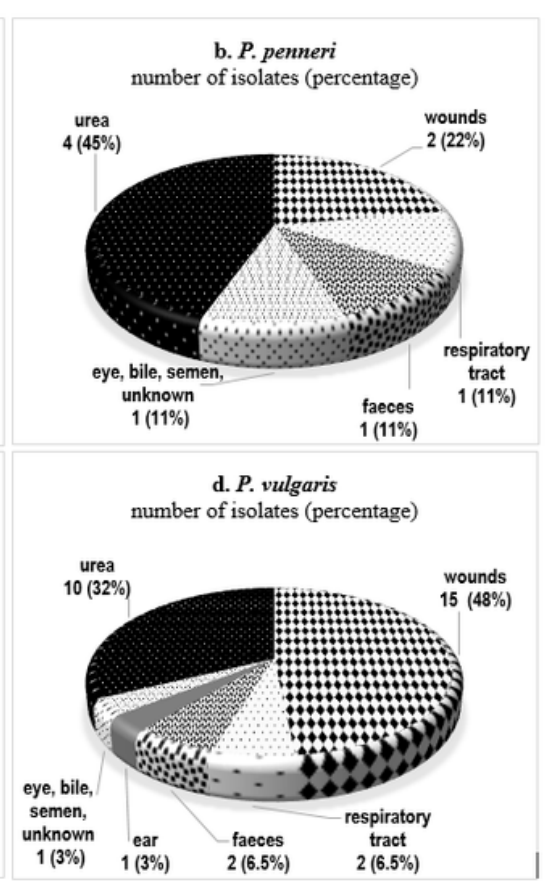




\section{Figure 1}

The sources of isolation of the whole collection of 617 Proteus spp. strains and separately: P. mirabilis isolates (a), P. penneri isolates (b), P. genomospecies isolates (c), and P. vulgaris isolates (d) [this work and 13-20].

a
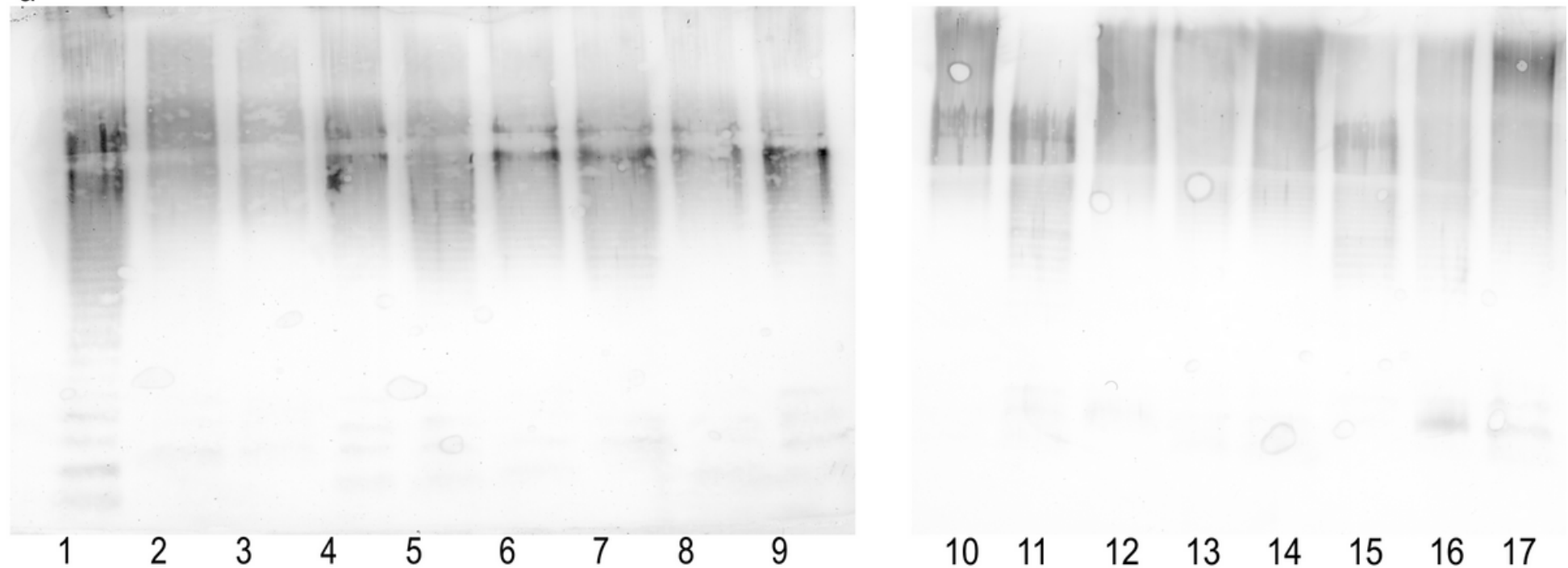

$\begin{array}{lllllllll}1 & 2 & 3 & 4 & 5 & 6 & 7 & 8 & 9\end{array}$

$\begin{array}{llllllll}10 & 11 & 12 & 13 & 14 & 15 & 16 & 17\end{array}$

b
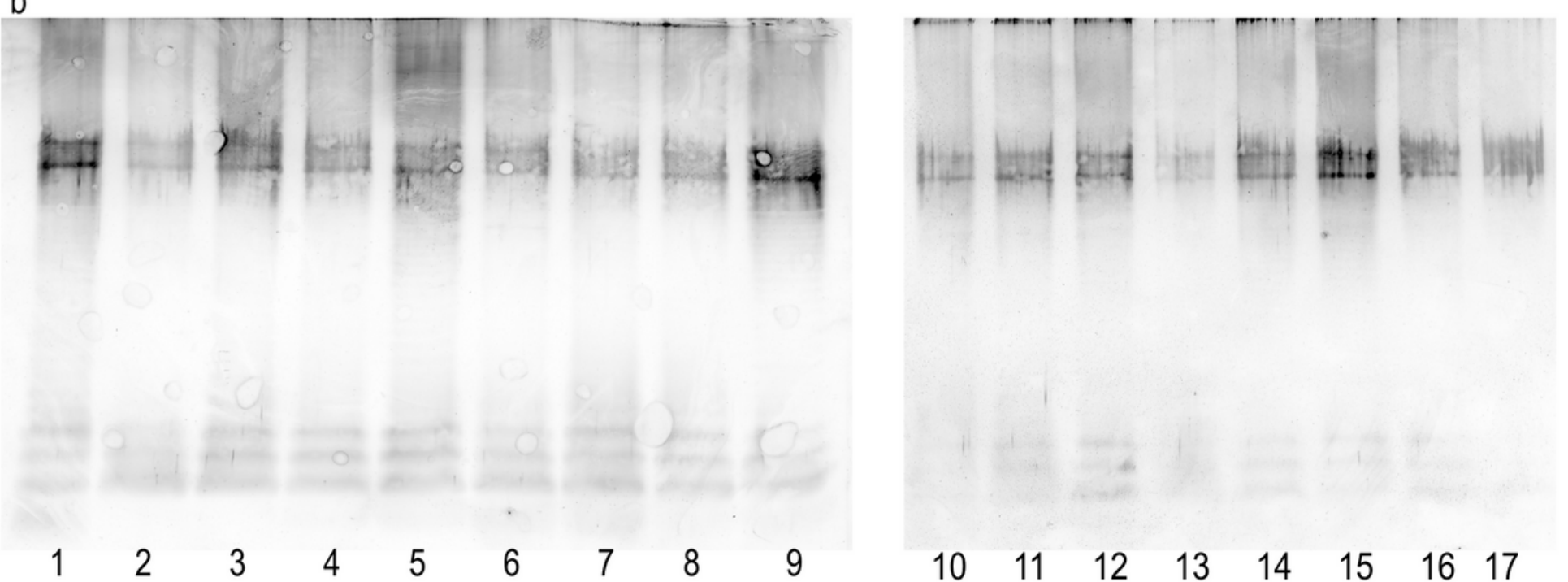

\section{Figure 2}

Western blots of 077 LPS (1) and proteinase K-treated biomasses (a) or LPSs (b) of the strains (2-17) classified to 077 serogroup with 077 -specific serum. 
a
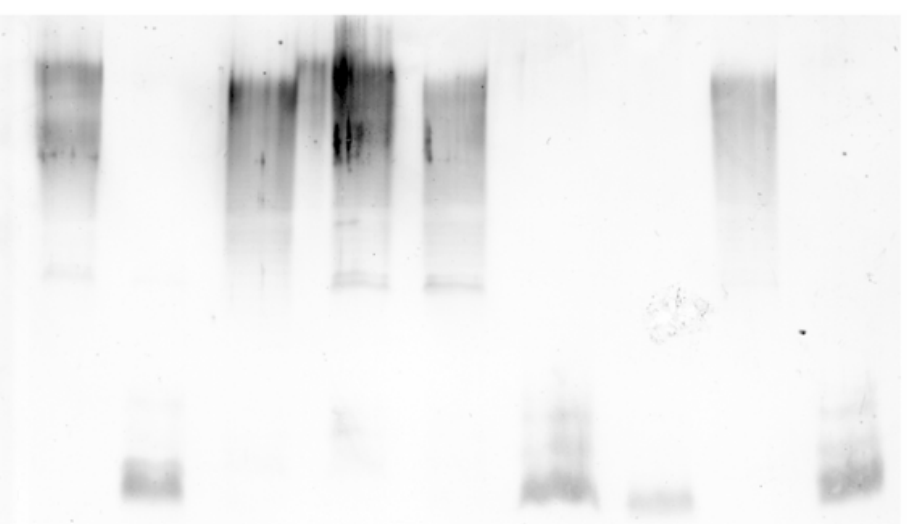

$\begin{array}{lllllllll}1 a & 2 a & 3 a & 4 a & 5 a & 6 a & 7 a & 8 a & 9 a\end{array}$

C
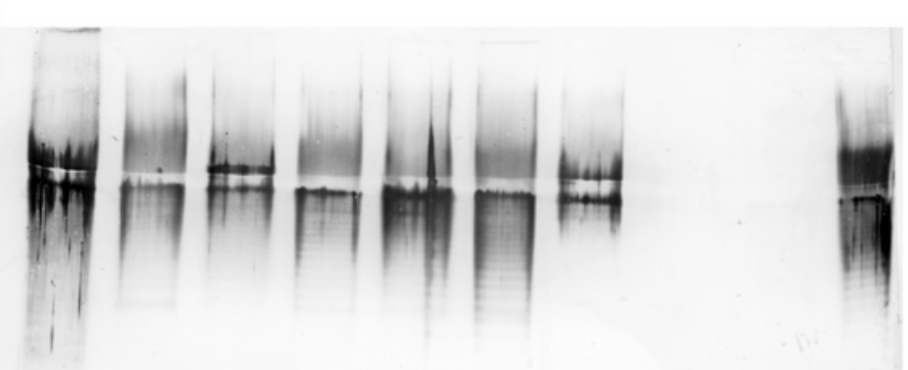

b

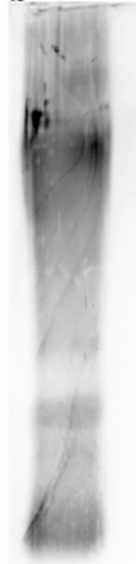

1b $\quad 2 b \quad 3 b \quad 4 b \quad 5 b \quad 6 b \quad 7 b \quad 8 b \quad 9 b$

d

$1 d \quad 2 d \quad 3 d \quad 4 d \quad 5 d \quad 6 d \quad 7 d \quad 8 d \quad 9 d \quad 10 d$
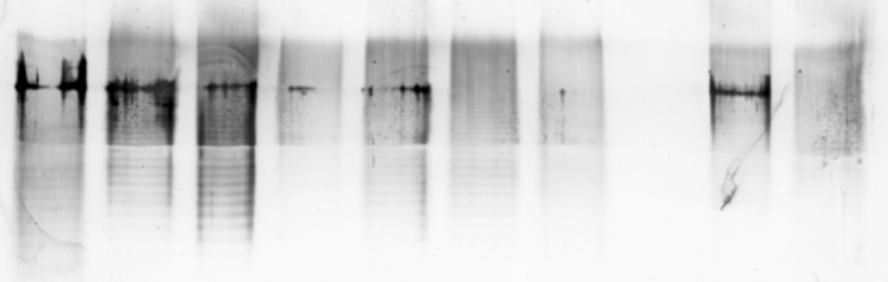

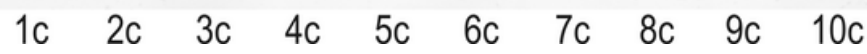

Figure 3

Western blots of homologous LPSs (1) and proteinase K-treated biomasses of selected strains (2-10) preliminarily classified to 03 serogroup (a), 010 serogroup (b), 028 serogroup (c), and 050 serogroup (d) with the respective antisera. 
a

b

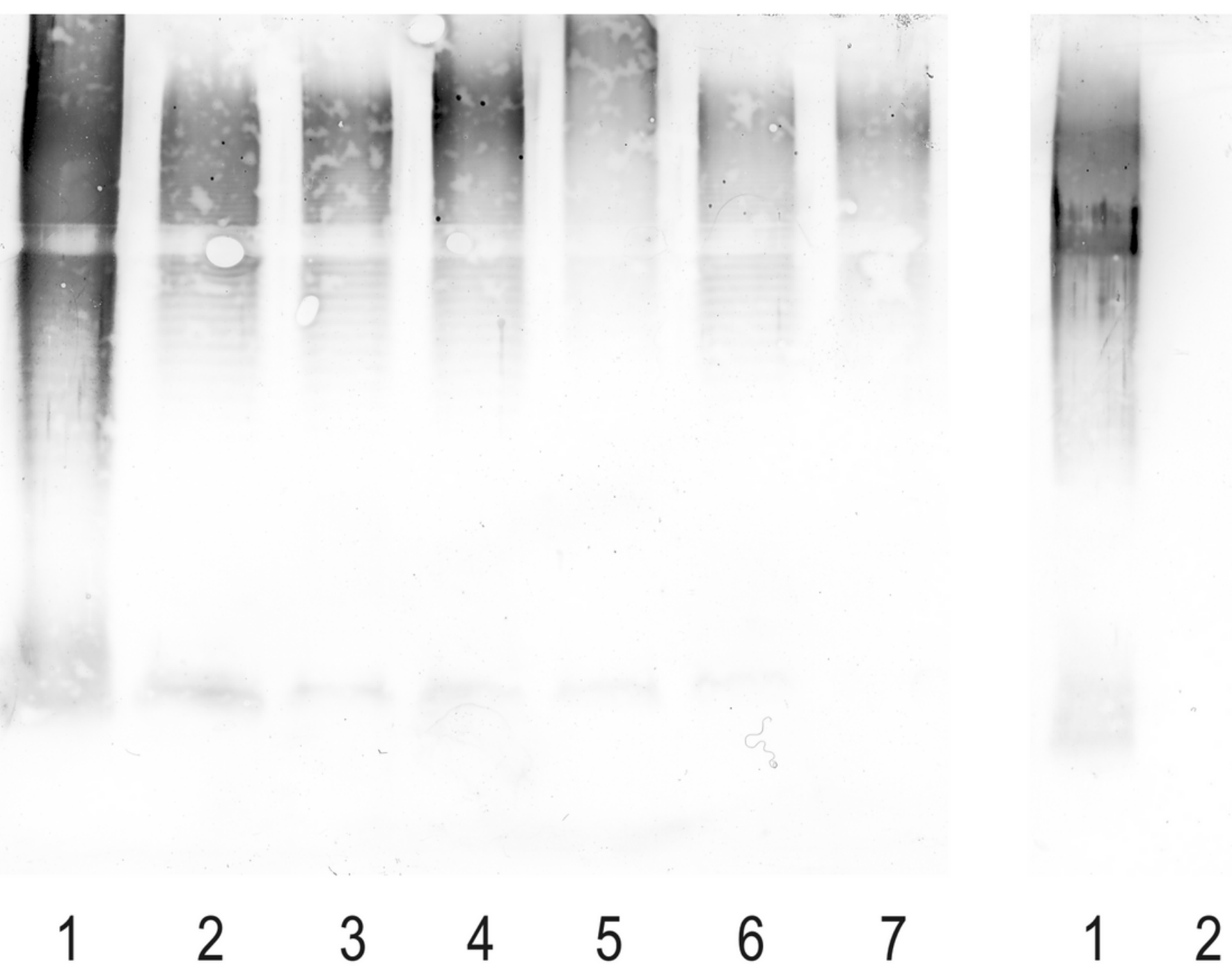

Figure 4

Western blots of 078 LPS (1) and proteinase K-treated biomasses of selected strains (2-6) classified into 078 serogroup with 078 antiserum (a) and 078 antiserum adsorbed by the strain 2 (b). 


\section{O SEROGROUPS}

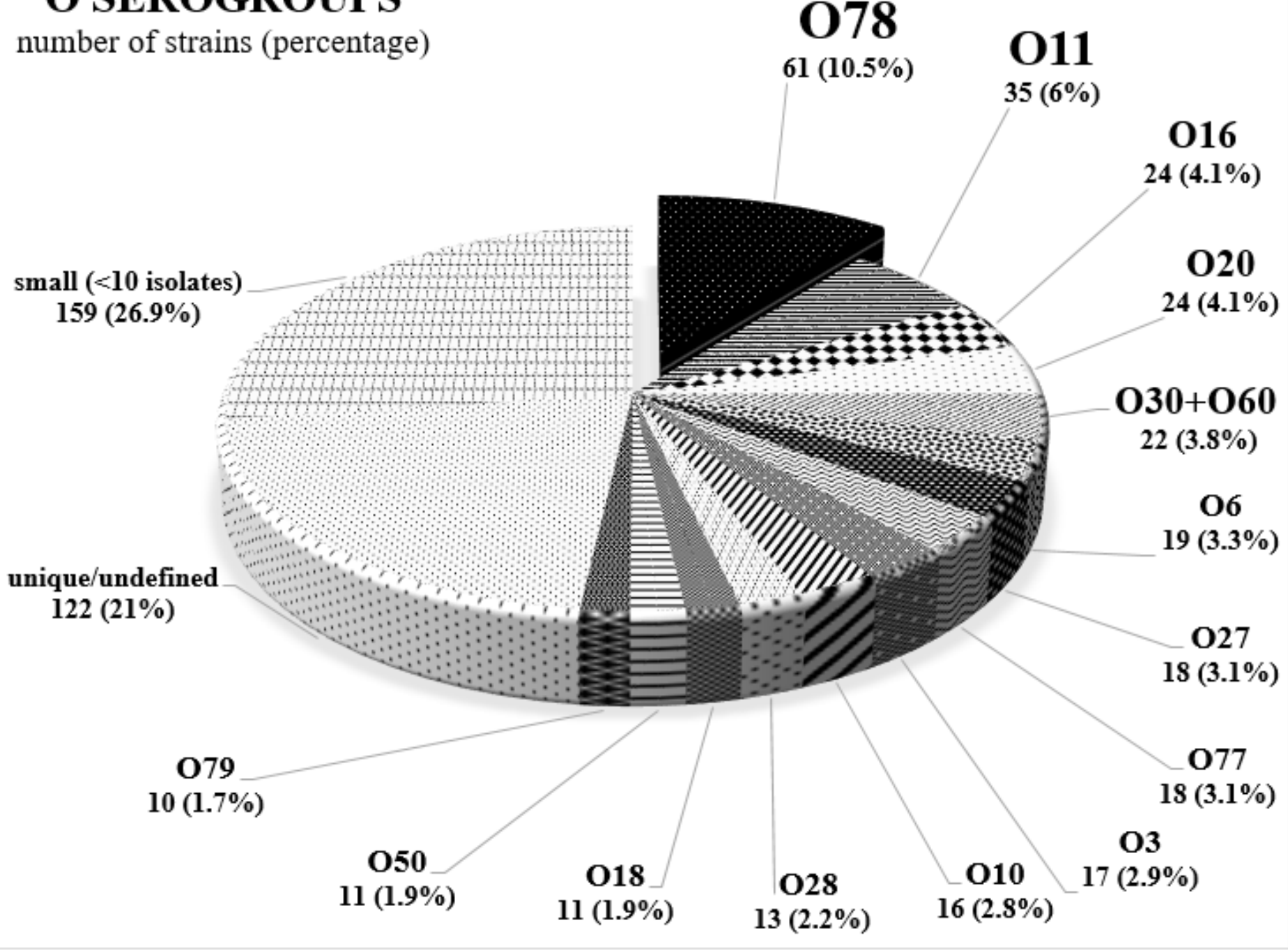

Figure 5

Classification of 580 S Proteus spp. strains into 0 serogroups [this work and 13-20].

\section{Supplementary Files}

This is a list of supplementary files associated with this preprint. Click to download.

- DrzewieckaTable3.docx 